\title{
CONTENÇÃO: UMA ESTRATÉGIA DE ESCRITA
}

\author{
DE CARLOS DE OLIVEIRA
}

Flávia Arruda Rodrigues ${ }^{1}$

RESUMO: O objetivo do trabalho é associar a contenção da escrita do escritor português Carlos de Oliveira com sua preocupação em ressaltar a carência da região da Gândara. Esse local é não só aquele em que o escritor passou sua infância, mas a ambientação que encontra para falar da precariedade e do obscurantismo de um Portugal sem perspectivas, oprimido pela ditadura do Estado Novo.

PALAVRAS-CHAVE: Carlos de Oliveira; contenção; Gândara; carência.

ABSTRACT: This work aims an association between the economy of words proposed by portuguese writer Carlos de Oliveira with his concern in highlighting Gândara's region social needs. This spot is not only where the writer was born, but the setting he finds for speaking of the poorness and the obscurantism of a Portugal with no perspectives, oppressed by Estado Novo's dictatorship.

KEYWORDS: Carlos de Oliveira, economy of words, Gândara, poorness.

A contenção é uma característica marcante da obra do poeta, escritor e ensaísta português Carlos de Oliveira, tendo apresentado variantes de maior ou menor grau conforme a fase da carreira e a pressão que o salazarismo lhe impôs nos anos de vigência do Estado Novo ${ }^{2}$. Ao longo de sua produção literária, que teve início com a primeira publicação de Turismo, em 1942, o autor prezou por uma progressiva economia de palavras e estruturas sintáticas, fazendo com que o mínimo de texto fosse responsável pela fruição máxima do leitor, no gozo estético ou na apreensão do conteúdo. Em seu romance de estréia, Casa na duna, chegado em primeira versão às livrarias logo no ano seguinte, 1943, essa preocupação também se deixa notar de maneira evidente: cortes sintáticos, temporais e de enredo têm a função de extirpar tudo o que, para Carlos de Oliveira, é supérfluo.

Antes de tecer comentários a respeito da capacidade de contenção do autor, torna-se indispensável retomar o que se pode chamar de obsessão de Carlos de Oliveira

\footnotetext{
${ }^{1}$ Mestranda em Letras/Estudos de Literatura Portuguesa (PUC-Rio).

${ }^{2}$ No decorrer de sua vida, Carlos de Oliveira acompanhou tanto a ascensão quanto o declínio do regime ditatorial português. O Estado Novo se estendeu de 1926 a 1974, tendo sido comandado por António de Oliveira Salazar entre 1933 e 1968 e por Marcello Caetano até sua derrocada. O autor nasceu em 1921 e morreu em 1981.
} 
pela constante reescrita de seus trabalhos - movimento que está associado tanto ao seu rigor ético e firmeza ideológica quanto à consciência de seu papel como um profissional inserido na sociedade portuguesa. Na nota final da última edição de Trabalho poético por ele revista, o escritor assinala: "O autor remodelou, incluiu, cortou (sobretudo cortou) o que lhe pareceu necessário para alcançar um conjunto mais equilibrado" (OLIVEIRA, 1992, p.12). Atenta a essa particularidade de Carlos de Oliveira, a professora e teórica portuguesa da literatura Rosa Maria Martelo ressalta em seu estudo "Casas destruídas", sobre Casa na duna e Finisterra. Paisagem e Povoamento, que "o romance Casa na duna, vindo a público quando o autor tinha apenas vinte e dois anos, fora já objecto de intensa reescrita aquando da terceira edição, em 1964" (MARTELO, 2000, p.252).

Em relação ao trabalho de Rosa Maria Martelo, que voltará a ser citado, faz-se, por hora, um necessário aparte no sentido de situar o lugar de enunciação deste entrelaçar de ideias: apesar de este trabalho aproveitar teorizações suas, tendo-as em alta consideração, discorda abertamente de uma, assim reproduzida: "Concomitantemente, e porque o Neo-realismo, como qualquer realismo, funciona por referência a uma 'ontologia forte', a própria possibilidade de uma poética realista é também questionada" (MARTELO, 2000, p.256). Fica, assim, claro que aqui se trabalha com a noção de que uma poética realista é possível, e concorda-se com Izabel Margato em sua problematização da frequente identificação do movimento neo-realista como um "realismo inferior", que deve ser lido como documento de época (MARGATO, no prelo). No entanto, essa discussão se mostrará mais útil em outra ocasião que não esta.

O que se pretende demonstrar é a estruturação da contenção como uma estratégia de escrita na prosa e na poesia de Carlos de Oliveira (já que uma é importante para o entendimento da outra), especialmente em Casa na duna. Na reunião de ensaios Aprendiz de feiticeiro, organizada pelo próprio autor, há um texto, "Micropaisagem", a respeito do livro de poesias homônimo, no qual ele discorre sobre seu ofício. Entre referências à elaboração lenta de uma obra, no vagar de uma "alquimia" dos papéis velhos e de "coisas reescritas à saciedade"; alusões ao trabalho de depuração do textos que, por serem tão concisos, têm carga explosiva proporcional à margem de silêncio em que são lidos, Carlos de Oliveira faz uma elegia da brevidade: 
Desses elementos se sustenta bastante toda a escrita de que sou capaz, umas vezes explícitos, muitas outras apenas sugeridos na brevidade dos textos. E disse sem querer uma palavra essencial para mim. Brevidade. (...) Que literatura poderia nascer daqui que não fosse marcada por esta opressiva brevidade, por este tom precário, demais a mais tão coincidentes com os sentimentos do autor? (OLIVEIRA, 1992, p.588)

Ao comentar exatamente esse trecho de Aprendiz de feiticeiro, Rosa Maria Martelo encontra três significados "correlatos e extensíveis" (MARTELO, 2000, p.253254) à poética do escritor, três princípios estruturantes do que ela entende ter sido denominado "essencial” por Carlos de Oliveira: carência, transformação e precariedade. O primeiro princípio, explica ela, exprime a solidariedade com os desapossados de si e do mundo; o segundo ativa um princípio do pensamento dialético com o qual se articula uma visão da História subordinada ao grande discurso clássico de emancipação, especificamente ao materialismo histórico; o terceiro "perspectiva subjetivamente os dois anteriores e introduz a dimensão individual, as 'obsessões pessoais' do escritor”.

Na palavra brevidade, Carlos de Oliveira faz convergir uma opção no conflito de classes, reportando-a à memória da carência observada na infância rural na região da Gândara; mas dessa memória vem também a evidência da permanente transformação do mundo físico, ("dunas modeladas, desfeitas pelo vento"), agora alargada a condição ontológica, e ainda a experiência da perecidade, o entendimento da vida como um "rumor precário". É este "o essencial" que a obra de Carlos de Oliveira permanentemente retoma, seja na poesia seja na ficção, primeiro apenas como tema, depois também como textura discursiva, através de uma linguagem que tende para a contenção, para a fragmentação e para a instabilidade inerente à reelaboração levada a cabo pela reescrita. (MARTELO, 2000, p.253-254)

E que mais queria Carlos de Oliveira, para além da demonstração sucinta e direta da falta de oportunidades, de informação e mesmo de soluções que tanto faltam ao povo da Gândara? No trecho de sua apresentação crítica à poesia de Carlos de Oliveira em que também comenta o livro de poesias Micropaisagem, Manuel Gusmão faz algumas considerações a respeito das razões que levam Carlos de Oliveira a dispor dessa brevidade. Para o crítico, ao falar de estalactites nesses poemas, o escritor leva o mundo mineral ao extremo, fazendo assim uma associação da petrificação da cal com a imobilidade do momento histórico (por sobre o qual paira o salazarismo). Essa colina oca, de flores calcárias, no entender de Gusmão, é a representação do presente histórico do poeta, "da insuportável cristalização (imobilidade) e aridez do tempo" (GUSMÃO, 
1981, p.51). Ainda nesse raciocínio a respeito do equilíbrio instável entre água e pedra, Gusmão conclui que, como há um movimento mínimo, lento, de condensação da água (e da liberdade) através dos milênios, também haverá o da dissolução dessas estruturas (e do aprisionamento), o retorno ao estado líquido.

Para que esse acordar se registe, aconteça para nós (no poema, na leitura dele), o poema percorrerá dois movimentos no seu próprio movimento: ir atrás (certamente também milênios antes) registar o modo como a água se cristalizou em pedra calcária; e, no futuro, buscar o momento, antecipado no poema, em que a pedra desenvolvendo-se, dissolvendo-se, libertará em água as flores retidas nas imobilizadas corolas de cal. (GUSMÃO, 1981, p.52)

Dessa forma, pela brevidade e pela contenção, Carlos de Oliveira alude, e bastalhe a alusão para reunir o sentimento geral do povo, em especial, o da Gândara, em sua voz. Tome-se, como exemplo, os dois primeiros parágrafos da abertura de Casa na duna:

$\mathrm{Na}$ gândara há aldeolas ermas, esquecidas entre pinhais, no fim do mundo. Nelas vivem homens semeando e colhendo, quando o estio poupa as espigas e o inverno não desaba em chuva e lama. Porque então são ramagens torcidas, barrancos, solidão naquelas terras pobres.

Ao fundo dum desses sítios, há uma pequena lagoa que o calor de julho seca. A aldeia chama-se Corrocovo e a lagoa sequer tem nome. Quando a água se escoa, a concha gretada está coberta de bunho. As mulheres ceifam-no, estendem-no ao sol, e entrançam esteiras que vão vender às feiras da vila de Corgos. (OLIVEIRA, 1992, p.603).

Numa breve análise, pode-se perceber como esses fatores se relacionam no processamento da estratégia de escrita do autor. A impressão que o texto passa é de que a carência e a precariedade estão por toda a parte do cenário que é apresentado. A única palavra com carga positiva de esperança é "espiga" e, mesmo assim, apenas quando o estio calha de poupá-la. A lagoa sequer tem nome. "Aldeola" indica uma concentração populacional de tamanho ínfimo, e tanto menos representativa para o resto do país na medida em que está "entre pinhais, no fim do mundo" - como também poderia estar, na visão de Carlos de Oliveira, o Portugal daquela época de pobreza, intensas desigualdades sociais, obscurantismo e repressão alienantemente mascaradas ou manipuladas pelo governo totalitário do Estado Novo. 
Pode-se argumentar, ainda, que essa economia literária também se manifesta nas circunstâncias da morte da personagem D. Conceição, que, em Casa na duna, são tratadas como desnecessárias. Nem por isso o leitor deixa de compreender que a até então desejada esposa de Mariano Paulo morre, causando um desequilíbrio emocional em toda a quinta, colaborando ainda para a criação de um ambiente de tristeza e resignação que será reforçado no desenrolar do romance. A gestação de D. Conceição serve como ilustração disso, já que é explicada em não mais que duas páginas, sem que a palavra "gravidez" ou quaisquer de seus sinônimos sejam usados.

No início do capítulo seguinte, sem mais explicações, Hilário, o fillho do casal, aparece como um rapaz já em idade escolar. E é só a partir das indagações do jovem ao Dr. Seabra, dezenas de páginas adiante, que se tem a informação de que D. Conceição morreu no parto, deixando ao filho, como herança, um sentimento de culpa que não é superado.

Em outro trecho, Mariano Paulo e Maria dos Anjos estão no quarto, primeiro prestes e, em seguida, logo após terem relações sexuais. São espionados, de dentro do outro quarto, por Hilário. O momento da cópula não aparece na narrativa econômica, mas o leitor tem como subentender que ele ocorreu.

Aguarda, imóvel, que Maria dos Anjos passe para a cama de Mariano Paulo. Ouve-lhe por fim os chinelos discretos. Ancas largas, sólidas, peito para dar mama a Corrocovo em peso, Maria dos Anjos pode parir uma dúzia de filhos. E vai pari-los, com certeza, para o prejudicar. Lá se desfaz a teoria de Mariano Paulo, lá se esboroa a quinta.

A luz acende-se no aposento do pai. O barulho da água despejada no balde significa que a pega se lavou e pouco tarde que volte ao próprio ninho, depois de conspurcar o alheio. Hilário levanta-se, atravessa o corredor no bico dos pés, empurra a porta do quarto dela e entra. (OLIVEIRA, 1992, p.707)

A mesma exiguidade de palavras e situações da estrutura desse episódio ocorre quando a morte de Hilário é narrada. A ação é descrita de forma igualmente contida, econômica:

As luzes do largo ocultas pelas árvores, o céu já sem estrelas, a madrugada ainda distante, rodeiam-no de treva. Apressa o passo, transpõe o portão. E nunca mais saberá como a água turva de que é 
feito se perdeu no mar. Uma dor fulgurante detém-no por segundos; e oscila, ajoelha, sem consciência de nada.

De manhã, os trabalhadores da quinta encontram-no ainda com a enxada que o matou enterrada de alto a baixo na cabeça. (OLIVEIRA, 1992, p.725)

Traça-se, assim, um paralelo, diante de tantos possíveis, entre prosa e a poesia de Carlos de Oliveira. A imagem de estalactites numa caverna, em Micropaisagem, tem semelhanças e diferenças com a duna na qual está instalada a casa-título do primeiro romance de Carlos de Oliveira. Ambas são feitas de mineral, calcário - evocando uma das imagens que perpassam toda a obra do escritor português (que costuma também retomar imagens como as de voo, lodo, musgo e infância). Porém, se a duna se ergue a partir da aldeia de Corrocovo, configurando um terreno não só móvel como instável para uma construção, os estalactites destilam água em ambientes subterrâneos, escondidos e sombrios. Se a primeira está exposta ao vento, a outra se resguarda em lugares cujo silêncio é quebrado pela ação da gravidade sobre os pingos d'água. Ainda no ensaio "Micropaisagem", Carlos de Oliveira, como Manuel Gusmão, relaciona sua obra a esse fenômeno de mineralização, permitindo-nos compreender, mais uma vez, que a preocupação com a condensação, de minerais ou palavras, perpassa todo o seu labor, toda a sua produção literária.

A matéria de alguns poemas da Micropaisagem, talvez mais decantada, mais indirecta, é a mesma. O que não quer dizer evidentemente que tenha desaproveitado experiências diferentes (ou parecidas) que a vida e a cultura me proporcionaram depois. (OLIVEIRA, 1992, p.586)

Por esse processo de decantação tão caro a Carlos de Olivera, pode-se fazer uma aproximação com as teorizações do escritor italiano (nascido em Cuba) Italo Calvino a respeito da exatidão, uma das cinco propostas por ele consideradas fundamentais para a literatura no século XXI, tendo sido trabalhadas no livro de ensaios Seis propostas para o próximo milênio ${ }^{3}$. Talvez fosse possível incluir Carlos de Oliveira na lista de escritores pretendida por Calvino (que afirma, por vontade própria, ser o primeiro a

\footnotetext{
${ }^{3}$ Os ensaios de Italo Calvino seriam lidos por ele numa série de conferências na Universidade de Harvard, no ano letivo de 1985-1986. Às vésperas de sua viagem aos Estados Unidos, cinco deles já estavam escritos e guardados numa pasta ("Leveza", "Rapidez", "Exatidão", "Visibilidade" e "Multiplicidade"). Porém, Calvino morreu em 19 de setembro de 1985, antes de apresentá-los. Do sexto ensaio, denominado "Consistency" no título original, havia apenas anotações prévias.
} 
figurar nesse rol). Na lista, seriam relacionados autores que, no século XX, partilhassem da imagem do cristal como fonte de inspiração, a partir de sua invariância e regularidade de estruturas específicas. No entender de Calvino, essa metáfora se opunha à da chama, que era, por sua vez, a representação da constância de uma forma global exterior, malgrada a incessante agitação interna. Nesse ensaio, "Exatidão", o escritor italiano explica que sua busca se bifurca em duas direções: de um lado, a redução dos acontecimentos a esquemas abstratos que permitam o cálculo e a demonstração de teoremas. Do outro, o esforço das palavras "para dar conta, com a maior precisão possível, do aspecto sensível das coisas" (CALVINO, 1990, p.88). É neste ponto que este estudo acredita residir a maior semelhança entre as estratégias de escrita de Italo Calvino e Carlos de Oliveira.

$\mathrm{Na}$ verdade, minha escrita sempre se defrontou com duas estradas divergentes que correspondem a dois tipos diversos de conhecimento: uma que se move no espaço mental de uma realidade desincorporada, em que se podem traçar linhas que conjugam pontos, projeções, formas abstratas, vetores de forças; outra que se move num espaço repleto de objetos e busca criar um equivalente verbal daquele espaço enchendo a página com palavras, num esforço de adequação minuciosa do escrito com o não-escrito, da totalidade do dizível com o não-dizível.São duas pulsões distintas no sentido da exatidão que jamais alcançam a satisfação absoluta. (...) porque ao se dar conta da densidade e da continuidade do mundo que nos rodeia, a linguagem se revela lacunosa, fragmentária, diz sempre algo menos com respeito à totalidade do experimentável. (CALVINO, 1990, p.88)

Assim se compreendem as razões que levaram Mário Dionísio a afirmar, em seus comentários no prefácio da terceira edição de Casa na duna, em 1964, que lia "este velho romance como um livro novo" (DIONÍSIO, 1964, p.35). Dionísio, ao falar de Carlos de Oliveira, ressalta que "a consciência crescente da importância decisiva do essencial, que o caminho de sua poesia documenta, eis a certeza que nos oferece o confronto da primeira Casa na duna (...) com esta Casa na duna que hoje nos oferece, vinte e um anos depois" (DIONÍSIO, 1964, p.37). É esse mesmo valor do essencial que estas páginas consideram decisivo para a compreensão da monumentalidade obra de Carlos de Oliveira.

\section{REFERÊNCIAS BIBLIOGRÁFICAS:}


CALVINO, Italo. Seis propostas para o próximo milênio. Trad. Ivo Barroso. São Paulo: Companhia das Letras, 1990.

DIONÍSIO, Mário. "Prefácio". In: OLIVEIRA, Carlos de. Casa na duna. $3^{\mathrm{a}}$ ed. Lisboa: Portugália Editora, 1964.

GUSMÃO, Manuel. “Apresentação crítica, selecção, notas e sugestões para análise literária de Manuel Gusmão". In: A poesia de Carlos de Oliveira. Lisboa: Seara Nova/Editorial Comunicação, 1981.

MARGATO, Izabel. "Notas sobre o Neo-Realismo português: um desejo de transformação". In: Revista Via Atlântica. São Paulo: USP, no prelo.

MARTELO, Rosa Maria. “Casas destruídas”. In: Línguas e Literaturas - Revista da Faculdade de Letras. Porto: Universidade do Porto, 2000. pp. 251-260. Disponível em http://ler.letras.up.pt/uploads/ficheiros/2999.pdf. Consulta em 18 jun. 2009.

OLIVEIRA, Carlos de. Obras de Carlos de Oliveira. Lisboa: Editorial Caminho, 1992. 